\title{
Facilitating Knowledge Transfer based on a Resource Based View of Tacit Knowledge Stock: A Skills Assessment Perspective
}

\section{Aastha Pant}

School of Management and Enterprise

University of Southern Queensland

Toowoomba, Australia

Email: Aastha.pant@usq.edu.au

\section{Anup Shrestha}

School of Management and Enterprise

University of Southern Queensland

Toowoomba, Australia

Email: Anup.shrestha@usq.edu.au

\section{Eric Kong}

School of Management and Enterprise

University of Southern Queensland

Toowoomba, Australia

Email: Eric.Kong@usq.edu.au

\section{Mustafa Ally}

School of Management and Enterprise

University of Southern Queensland

Toowoomba, Australia

Email: Mustafa.ally@usq.edu.au

\begin{abstract}
Resource Based View posits the use of internal resources for competitive advantage which is often evaluated using four questions on value, rarity, imitability and organisation, also known as the VRIO framework. We focus on the organisational resource of tacit knowledge - characterized by knowledge that is difficult to transfer. Knowledge transfer begins with the identification of knowledge stock. Using the Design Science Research Methodology, we develop and evaluate a skills assessment method to measure tacit knowledge stock of an organisation based on the Skills Framework of the Information Age (SFIA). The method is evaluated in an Australian bank during its digital innovation initiative. We found that knowledge transfer is most effective when the person or party that is transferring knowledge has prior understanding of the receivers' knowledge stock. This finding has significant implications to practice in the area of knowledge management.
\end{abstract}

Keywords resource-based view, VRIO framework, knowledge management, Skills Framework for the Information Age, design science research 


\section{Introduction}

The Resource Based View (RBV) theory by Barney (1991) states that organisations must use their internal resources for their sustainable growth. Among several tangible and intangible resources used by an organisation, knowledge is a critical resource that promotes sustainable competitive advantage (Harrison et al. 2001). Knowledge management is gaining prominence within the areas of strategic management and innovation (Rupietta and Backes-Gellner 2017). During knowledge management, the concept of knowledge stock and knowledge transfer are often used to measure effective dissemination of knowledge in an organisation (Kyriakopoulos and De Ruyter 2004). Generally, at an individual level, knowledge stock may refer to (a) information contained in the mind of a person i.e. tacit knowledge or (b) information which can be clearly documented i.e. explicit knowledge (Machlup 1979).

Knowledge stock of a person is static in nature and remains under-utilised unless transferred to others effectively (Lai et al. 2016). Knowledge transfer is typically a spiral flow of knowledge through people, groups or firms (Nonaka 1994). Knowledge transfer among employees within an organisation enhances a healthy knowledge management culture (Lam 2005). Employees that continuously acquire new knowledge enable external knowledge acquisition that helps to effectively transfer knowledge within an organisation (Lopez-Saez et al. 2010). Although knowledge transfer is a heavily researched topic, it is a challenge for many organisations to execute it in practice (Frank et al. 2015; Minbaeva et al. 2014). Moreover, there is a general consensus that tacit knowledge is more difficult to transfer as compared to explicit knowledge because of the challenge in codifying tacit knowledge (Inkpen and Pien 2006).

Research has suggested various factors that are responsible for the success of tacit knowledge transfer, viz. peoples' knowledge levels, interactions, and motivation for knowledge transfer, absorptive capacity and the existing knowledge stock (Gupta and Govindarajan 2000). Knowledge stock can be represented by skills ingrained within an organisation's human resources. In our research, we refer to knowledge stock' of people in terms of their current digital skills. Digital skills are critical for all careers in today's ICT-empowered business ecosystem (Shrestha et al. 2017). Likewise, the importance of correctly identifying peoples' current skills to enable knowledge transfer has been highlighted by various studies (Leonard-Barton 1995; Prince et al. 2015). However, there are scant studies that investigate the measurement of peoples' skills as knowledge stock and its link to knowledge transfer. Consequently, this research attempts to answer the research question: How can peoples' skills be measured as tacit knowledge stock, and then subsequently enable knowledge transfer? This research question is divided into two sub questions for granularity, which are:

RQ1: Can tacit knowledge stock be measured by skills of employees in an organisation?

RQ2: How does tacit knowledge stock enable knowledge transfer?

To answer the research question, we developed a skills assessment method that uses the Skills Framework for the Information Age (SFIA) to measure tacit knowledge stock of organisational staff. The VRIO framework by Barney (1991) is widely used to evaluate an organisation's resources in terms of its value, rarity, imitability and organisation. We evaluated the method by reviewing its reported tacit knowledge stock based on the VRIO framework. The organisational setting for the evaluation is a realworld digital innovation project in an Australian bank in 2018. Key stakeholders of the project were interviewed to investigate how the reported knowledge stock may enable knowledge transfer within the organisation.

The paper is organised as follows. First, a brief description of the relevant knowledge management and skills assessment principles is presented followed by an overview of the RBV theory and the VRIO Framework. The design principles for the development of the skills assessment method is presented using a conceptual model for this study. Based on the design principles, we explain our Design Science Research (DSR) project in terms of development and evaluation of the method to identify knowledge stock based on the digital skills of ICT professionals and to understand its impact on knowledge transfer. Finally, research findings are discussed and implications to research and practice are offered.

\section{Literature Review}

\subsection{Knowledge as a Resource}

The term knowledge' refers to a justified belief that expands the abilities of a person to perform their activities effectively (Huber 1991; Nonaka 1994). According to Leonard and Sensiper (1998) , knowledge is relevant and actionable information which is partly based on the experience of a person. There are two types of knowledge in an organisation: tacit and explicit (Nonaka 1994; Polanyi 2009). Tacit 
knowledge refers to a composition of cognitive and technical elements where cognitive elements include views and thoughts of a person (Spender 1996). On the other hand, the technical elements comprise skills and ideas about a specific area (Nonaka 1994). According to Spender (1996), tacit knowledge is the knowledge which is not explicated yet. For example, the skills and abilities needed to master a musical instrument cannot be fully expressed in words, hence it is a tacit knowledge. Likewise, explicit knowledge refers to the knowledge which can be expressed and transferred in symbolic forms or using simple language (Alavi and Leidner 2001). An example of explicit knowledge is an owner's manual of a product that explains how to operate it, where the knowledge is presented in a codified form. Transferring tacit knowledge is more complicated as compared to explicit knowledge transfer (Dhanaraj et al. 2004). It is because tacit knowledge is progressively increased via interactions and observations whereas explicit knowledge is relatively easy to learn and code (Doz et al. 2001).

Among various factors influencing knowledge transfer, a persons' tacit knowledge stock is an important one (García-Morales et al. 2008; Gupta and Govindarajan 2000). The research conducted by Empson (2001) reported that people inhibit knowledge transfer when their level of knowledge do not match with others knowledge level with whom they are sharing. Huckaby and Christensen (2012) pointed out that there is a strong relationship between attitude and the intention of people to transfer their knowledge. Negative attitude towards transferring knowledge is caused by differences in the knowledge stock (Cohen and Levinthal 2000). The research conducted by Fullwood et al. (2013) found that academic leadership, represented as superior knowledge stock, plays a vital role in transferring knowledge. A taxonomic analysis by Frank and Ribeiro (2014) identified four major factors influencing knowledge transfer including personnel, technology, work design and external environment sub-systems. According to this research, identifying technical and systematic knowledge stock of the team members was the most important factor that could influence knowledge transfer between the teams. Power and Cormican (2015) also mentioned that knowledge transfer is simpler when organisations are aware of the knowledge stock of their staff. Moreover, identification of knowledge stock of organisational staff before recruitment helps to select right staff for knowledge transfer within the organisation (Power and Cormican 2015).

Extant literature on knowledge as a resource has confirmed the importance of knowledge stock identification to enable knowledge transfer. Nevertheless, there is a lack of research that investigates the "methods" to measure tacit knowledge within an organisation. A recent research demonstrated the lack of the use of IT in identifying tacit knowledge stock (Pant et al. 2018). Potential methods to identify the knowledge stock of an employee are accessing past projects and profiles, analysis of existing documents produced by the employee and staff relationship analysis (Newk-Fon Hey Tow et al. 2012). Assessing current staff skills is one of the most efficient and accurate methods to identify organisational knowledge stock (Bartram 2004; Shrestha et al. 2017). We discuss skills assessment in more detail next.

\subsection{Skills Assessment}

Skills assessment is the process of determining the competency level of a person in terms of ability to perform relevant activities. Such assessment may use ICT tools and methods to obtain the overall profile of a person and their relevant capabilities (Patterson et al. 2001). A competency based management (CBM) method allows organisations to assess the human capacities based on their current skills that are required to achieve organisational goals (Tripathi and Agrawal 2014). Many attempts have been made to explain the skills assessment process to identify knowledge stock (Lawler III 1994; Tripathi and Agrawal 2014). However, there appears to be limited attempt to propose ways of doing this, consequently there is a lack of empirical evidence to demonstrate skills assessment as an effective method of knowledge stock identification (Shrestha et al. 2017).

Skills assessments have several benefits both at the individual and organisational level because measurement of skills help individuals plan their careers and organisations can manage their collective knowledge stock for long term organisational benefits (Bartram 2004). However, the process of adopting skills assessments to measure knowledge stock at organisational level is largely untested in a research setting (Shrestha et al. 2017). This research measures the skills possessed by staff of an organisation to identify their knowledge stock and then explore the extent to which it facilitates knowledge transfer. To address this requirement, the skills assessment method was developed using the Skills Framework for the Information Age (SFIA) to review digital skills within the ICT setting.

The SFIA, originally proposed in 2000, is a popular and well-established framework to identify digital skills and competencies for ICT professionals. Organisations and individuals from over 150 countries use this framework to map their skills set. A major activity in this framework involves open consultation and obtaining input from those who possess practical experiences in the management of skills in industries and educational institution. A standard report can be produced for the skills possessed by an 
individual in order to help them in their career aims (SFIA 2018; von Konsky et al. 2016). A total of 97 skills are defined in SFIA in six categories, namely, Strategy and Architecture, Business Change, Solution Development and Implementation, Service Management, Procurement and Management Support and Client Interface (SFIA 2018). There are seven levels of increasing responsibilities for all the skills: follow, assist, apply, enable, ensue/ advise, initiate/influence and set strategy. Each skill is described based on the responsibility level of autonomy, influence, complexity and business skills needed by the employees. This research proposes skills assessment as a critical method to measure tacit knowledge stock. Assessment as a method has been previously researched in the area of knowledge management to enable process improvements in IT Service Management (Shrestha et al. 2018). Knowledge is considered a significant resource for organisations and it is often studied from a resourcebased view using the VRIO framework. A brief overview of these terms follows next.

\subsection{Resource Based View of the Firm (RBV) and VRIO Framework}

RBV states that it is very important for an organisation to utilise its core competencies as it increases organisational productivity (Barney 1991). Internal resources of an organisation are given the highest priority by RBV that promotes a resource-based model. According to the model, there are two types of resources: (1) tangible resources such as physical assets of an organisations, and (2) intangible resources, such as brand reputation, trademarks and intellectual properties (Wernerfelt 1984). It also assumes that organisational resources are heterogeneous and immobile in nature. The term heterogeneous' means that an organisation's intellectual property varies from one organisation to another. The term 'immobile' means that those properties cannot move from one organisation to another without one's efforts in transferring them (Barney 1991). Based on the 'knowledge as a resource' view, it is clear that the skills and knowledge of the organisational staff are critical factors for organisational growth (Tzabbar et al. 2008).

VRIO is an abbreviation for a four-question framework about a resource to determineits worth in terms of Value, Rarity, Imitability, and Organisation. The VRIO Framework was developed by Barney (1991) which states that the resources must not only be valuable, rare, and costly to imitate to enhance organisational growth, but the organisation should also utilize the resources properly to takeadvantage of it. Based on the concept of dynamic capabilities, Eisenhardt and Martin (2000) argue that organisational strategy and processes are as important as the organisational resources, because they enable resources manipulation to enhance organisation's performance. The main focus of the empirical studies were on the direct connection between resources configurations and organisational performances, whereas there is limited attention towards effective utilization of resources (Armstrong and Shimizu 2007).

Using the language from the VRIO framework, it can be concluded that research studies have limited focus on the interrelationship between a firm's organisation ('O') and its resources ('VRI') to explain its performance even though positive impact of effective utilization of firm's resources has been established (Cockburn et al. 2000). Consequently, having knowledge resources that are valuable, rare and difficult to imitate are not enough for superior performance of the organisation. Methods to utilize knowledge resources that can be codified easily (i.e. explicit knowledge) are abundant in the information systems and knowledge management literature (Dayasindhu 2002). However, knowledge resources that are hard to codify, such as tacit knowledge stock must also be utilized for knowledge transfer within an organisation. An organisation's knowledge stock can only be utilized optimally when it can be transferred because knowledge stock is static in nature and has limited value unless transferred (Lai et al. 2016). RBV and VRIO framework offer design principles with a theoretical input to justify and explain this design science research project. Methodology is discussed in some detail next.

\section{Design Science Research Methodology}

A key objective of a Design science research (DSR) project is to generate and evaluate artefacts that focus on solving organisational issues (Hevner 2007). This research developed and evaluated a skills assessment method to identify the knowledge stock of ICT professionals of an organisation. Consequently, this research is best suited as a DSR, with the method as the artefact proposed to resolve issues surrounding knowledge stock identification and its implications to knowledge transfer. The design principles, development, demonstration and evaluation of the artefact are presented next.

\subsection{Design Principles for the Artefact}

RBV (Barney et al. (2001) suggests organisations must focus on managing their resources to enhance their growth. People are considered the most important resource because they possess intellectual 
capital (Edvinsson and Malone 1997) and knowledge (Grant 1996) to offer competitive advantages. The knowledge based theory by Grant (1996) states that organisations exist and grow only when there is better integration and application of the knowledge present within them. Using RBV as the kernel theory, we recognize skills as a key organisational resource to represent knowledge stock and propose our first design principle: tacit knowledge stock is an organisation resource measured by skills assessment.

Likewise, the VRIO framework (Barney 1991) demands that a firm's resource must be valuable, rare, difficult to imitate and well-organised by the firm to obtain maximum benefits. Considering that tacit knowledge is more difficult to transfer than explicit knowledge (Inkpen and Pien 2006), we present our second and final design principle: knowledge transfer is enabled by tacit knowledge stock.

Based on the two design principles, a conceptual research model has been developed (Figure 1) to explain the rationale and process of artefact development and evaluation.

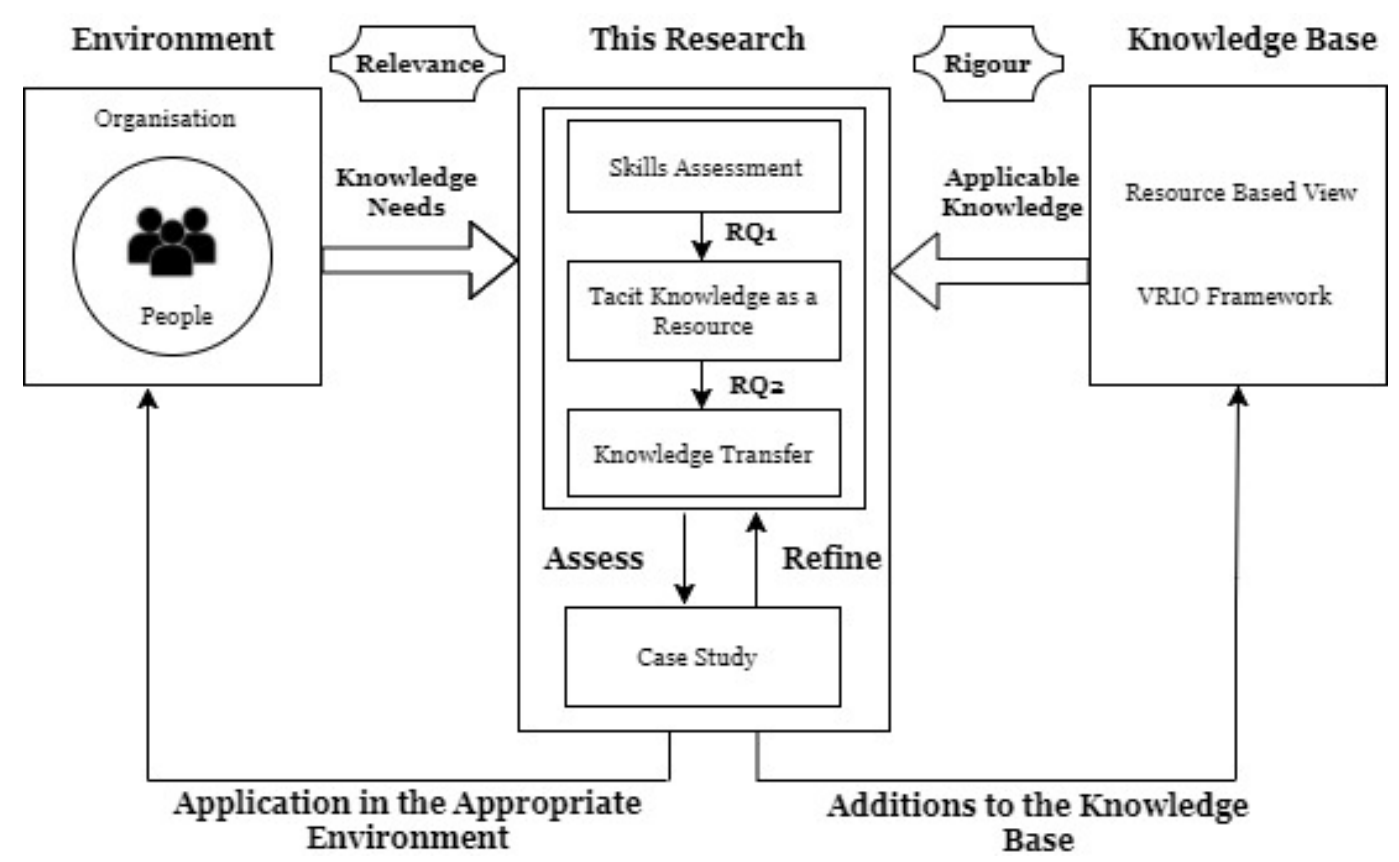

Figure 1: Conceptual Research Model adapted from Hevner (2007)

Figure 1 is based on the three-phase DSR cycles by Hevner (2007). The three phases in the cycle include: (i) Relevance Cycle, (ii) Design Cycle and (iii) Rigour Cycle. The three cycle DSR study has been applied previously in a research area of automating assessments in order to demonstrate relevance and rigour of research activities (Barafort et al. 2018). Similarly, we apply Hevner (2007) methodology in this research. The 'Relevance cycle' for this research deals with the alignment of the organisation with its knowledge needs whereas the Design cycle deals with the development and evaluation of the artefact to provide a solution to the existing research problem in the area of knowledge management. The artefact is a skills assessment method to measure the knowledge stock of people in a case study organisation to explore its importance in knowledge transfer. In doing so, this research is fulfilling one of the knowledge needs of the case study organisation. Moreover, the 'Rigour cycle' in the model refers to the theory and framework used to support the research which includes the RBV and the VRIO Framework. The application of the theory and framework adds knowledge and provides rigour to the knowledge base of this research.

\subsection{Artefact Development and Demonstration}

ICT skills are one of the most powerful skills required by organisations both currently as well as in future (Colbert et al. 2016). For our study, we developed a skills assessment method that measures the digital skills possessed by individuals and, in so doing, can help decision makers identify their collective knowledge stock to enable knowledge transfer. The method uses the SFIA framework because of its popularity and reliability (SFIA 2018). The method was developed with our Australian technology partner that provides world-leading cloud-based assessment services (Shrestha et al. 2017). 


\subsection{Artefact Evaluation}

\subsubsection{Case Selection and Participants}

Our case study organisation is an Australian bank that was rolling out a digital innovation project as a strategic initiative championed by its CIO. Given the choice of SFIA, we selected this case study where research participants must possess superior levels of digital and IT skills. Staff experiences in using skills assessment method can provide insight into the role of the method to measure their individual knowledge stock. Similarly, we sought input through interviews of the senior managers of the digital innovation project to gain their perspectives on how the identified knowledge stock might enable knowledge transfer, as required for digital innovation activities during the project.

\subsubsection{Data Collection}

All the ICT staff at the case study were invited to participate in the study. There are seven ICT teams in the project: Strategy and Architecture, IT Administration, IT Service Delivery, IT Infrastructure \& Security Services, Banking Payments \& Ancillary Systems, IT Projects and Digital Banking Systems. There were 9 to 21 employees in each team. A total of 14 employees across all teams were intensively involved with the skills assessment exercise. We organized a one-hour workshop at the case study site to help the participants understand the SFIA framework and train them to use the method that was executed in April 2018.

We presented individual skills profile to the ICT staff and a collective snapshot of skills summary, as identified tacit knowledge stock, to the senior managers of the project. We obtained the perceived views of the participants on the effectiveness of skills assessment exercise to measure their knowledge stock. Further in-depth semi-structured interviews with senior managers provided an insight on how the identified knowledge stock could help in knowledge transfer within the context of digital innovation at the case study.

\section{Result and Findings}

Skills assessment is helpful assessing one's skills at both individual level and organisational level (Bartram 2004). Firstly, research participants were interviewed about the effectiveness of skills assessment to identify their knowledge stock at an individual level. Majority of the employees (10 out of 14) found the method was very effective in identifying their knowledge stock at the individual level. Four employees thought that the method was useful for the managerial staff at the organisational level only. Table 1 provides the summary of the evaluation results of the effectiveness of the skills assessment method.

Level of skills assessment

Selected key comments

\section{Individual level}

- planning career

- identifying skills gaps

- Getting an overall picture of the individual knowledge stock
- “... I can identify the skills and knowledge stock which I lack or which I can pursue in future to progress my career."

- "If you havea career goal and trying to plan a career, I think it will bevery useful because it will help you identify the areas where you need to work on."

"...provides me some directions to obtain a certain training or knowledge in my areas."

\section{Organisational level}

- useful to the managerial staff only

- getting an overall picture of the collective knowledge stock

- recruiting new employees based on theidentified knowledge gaps

-“...an overall picture of what the employees are skilled with. It is a great tool for the management."

-“.. useful for the management staff. I think it helps managerial staff to know where they areand what they want to do in future, based on the knowledge stock of their staff."

"...assess the potential employees to determine what skills they have and what skills they can bring to the organisation."

Table 1. Evaluation Results of Skills Assessment Method 
Secondly, the research participants were asked a series of questions to determine in what ways the representation of their knowledge stock can help in knowledge transfer. Three key themes emerged from our data analysis: person-organisation fit; sender's willingness; and prior understanding of receiver's knowledge stock. These themes are briefly discussed next.

\subsection{Person-Organisation Fit}

Person-organization fit was originally studied by Kristof (1996). According to this theory, there must be compatibility between a person and an organisation to enhance the growth of both entities. It means that it is not enough to have an employee with excellent knowledge stock but they must have abilities to fit organisational demands. We found that effectiveness of knowledge transfer depends on the fit of the person in his or her job and roles within the organisation.

- "[knowledge transfer] can depend on what your role is in an organisation. For example, if you have a particular set of skills that require you to do your job that might not be the same skills set for another person... knowledge stock identification alone cannot facilitate knowledge transfer."

\subsection{Senders' Willingness}

Past research have investigated sender's willingness in knowledge transfer (Héliot and Riley 2010; Wiewiora et al. 2013). This research supports previous studies and suggests that if the sender is not willing or interested to transfer knowledge, understanding knowledge stock in itself is not sufficient.

- "[knowledge transfer] depends on whether a person wants to share knowledge to expand into different roles in the organisation after identifying his/ her knowledge stock."

\subsection{Prior Understanding of Receiver's Knowledge Stock}

Majority of research participants suggested if they want to transfer knowledge, they would like to know the knowledge stock of the person beforehand to whom they are sharing their knowledge. It appears to be a very practical suggestion but surprisingly we did not find much research in this area.

Cummings and Teng (2003) states that the knowledge stock of the sender must be made accessible to the receiver to enable knowledge transfer between them whereases Gupta and Govindarajan (2000) mentioned that knowledge transfer is dependent on the knowing the value of sender's knowledge stock by the receiver which is similar. However, limited studies associate knowledge transfer effectiveness with receiver's knowledge stock.

-“...if I know what other people's knowledge areas are, then it certainly would help to go to the right person to obtain or give knowledge."

- "If the profiles of other team mates are shared with us, then certainly yes [enabling knowledge transfer]. That will help us to gain the knowledge from that person if we are going to some other specialized projects."

The results are further discussed in the next section.

\section{Discussion}

Our results complement research conducted by Bartram (2004) and suggest that skills assessment is a useful method to identify knowledge stock at individual as well as organisational level. However, our findings confirm that people typically find skills assessment is only useful for individual knowledge stock. For example, the skills assessment enabled case study participants to plan their career. Benefits to the case study organisation itself due to the recognition of collective knowledge stock were not appreciated.

Wiklund and Shepherd (2003) argue that if the collective knowledge resource of a firm is utilized properly, it enhances firm's orientation and performance. Likewise, the research conducted by Nickerson and Zenger (2004) stated that managers must identify and utilize the overall knowledge stock of the firm because it helps in solving critical problems of the firm using limited time and resources. Although organisations benefit greatly by their collective knowledge stock, organisations are missing out on effectively disseminating them.

Barney (1991) VRIO framework states that organisations can gain maximum benefits if its resources are valuable (V), rare(R), difficult to imitate (I) and properly utilized by the organisation $(\mathrm{O})$. The fourth property of an organisational resource, i.e. ability to utilize the resources (O) is found to be most challenging (Chatzoglou et al. 2018). Our results complement Power and Cormican (2015)'s argument 
that understanding knowledge stock of all employees in an organisation enables knowledge transfer. The empirical data from our research demonstrate the importance of knowledge stock to facilitate knowledge transfer. Following the VRIO framework, our research confirm when collective knowledge stock of an organisation is identified, this will facilitate knowledge transfer leading to superior performance, akin to research conducted by (Argote and Ingram 2000).

We introduced three new themes that emerged while exploring the relationship between knowledge stock and knowledge transfer. Based on the theme of 'person-organisation fit', it is critical that knowledge stock is relevant to the person's job and current role in the organisation. J udge (1994)'s theory of work adjustment confirms that person-organisation fit positively impacts an employee's career success and supports organisation growth. Associating this theory with the VRIO framework, tacit knowledge stock can be considered valuable, rare and difficult to imitate (VRI) on its own, however it can only be organised $(\mathrm{O})$ when we determine best fit for the organisation and its staff. Implications to practice include creating favourable working environment where employees are aware of their roles and responsibilities in the organisation to enable knowledge transfer.

Moreover, our findings support common understanding that during knowledge transfer, willingness of the person or party that transfers their knowledge, i.e. sender's willingness, is a very important factor. Past research confirms that without the motivation of the sender, there cannot be effective knowledge transfer in any organisation (Gupta and Govindarajan 2000; Héliot and Riley 2010; Wiewiora et al. 2013). Our findings also support the fact that the sender must have vested interest in knowledge transfer.

Lin (2007) states that the use of ICT helps knowledge receiver to recognize the sender's knowledge stock. This research does not explore identifying the receiver's knowledge stock. Likewise, it has been proven that collective knowledge stock has a positive impact on knowledge transfer (Wang and Noe 2010). Prior research suggests that based on ones' own knowledge stock, a sender perceives that the receiver will benefit from knowledge transfer without recognizing the receiver's knowledge stock. In these cases, knowledge transfer occurs due to the perceived beliefs of employees that their knowledge stock is useful to other people especially in a professional network. However, the sender is not aware of the receiver's knowledge stock in all these studies (Chiu et al. 2006; Siemsen et al. 2007; Wasko and Faraj 2005). However, we found that prior understanding of receiver's knowledge stock could play a critical role in knowledge transfer.

Consequently, as an important implication to practice, we argue for recognizing the knowledge stock of the receiver before knowledge transfer is considered by the sender. A number of studies have proposed that knowledge transfer is relatively easier when knowledge stock is known (Lin 2007; Wang and Noe 2010). However, this relationship has been explored based on self-awareness of knowledge stock of the sender but not from the perspective of the receiver. This is perhaps due to the assumption that it is not possible to recognise the knowledge stock of others. This assumption, however, does not hold true since our research has enabled identification of knowledge stock using a skills assessment method. At an individual level, such knowledge stock can be shared across key stakeholders for the purpose of effective knowledge transfer. Therefore, combined with the factor of sender's willingness, we believe that our argument: prior understanding of receiver's knowledge stock enables effective knowledge transfer, is justified.

\section{Conclusion}

Based on the RBV theory and VRIO framework, the objective for this paper was to understand how a skills assessment method can identify knowledge stock and how effective is such knowledge stock towards knowledge transfer in an organisation. Using Design Science Research Methodology, we developed the skills assessment method using the SFIA framework, and later evaluated it in an Australian bank. The method measured the knowledge stock of ICT employees of the organisation in terms of their digital skills. Evaluation of the method was based on semi-structured interviews to determine how knowledge stock could enable knowledge transfer.

We found that skills assessment is useful to measure knowledge stock, however such benefits are highly recognized at the individual level rather than for the entire organisation. This is a missed opportunity for effective use of knowledge stock towards knowledge transfer. Our research work also concluded that knowledge transfer is effective when there is some prior understanding of the receivers' knowledge stock. This finding is significant as prior research has not yet studied this factor, probably due to the assumption that others' knowledge stock may not be recognized. The use of the skills assessment 
method in this research has created an opportunity to identify knowledge stock, hence recognize receiver's knowledge stock for effective knowledge transfer.

We realise the need of further research to empirically test the relevance and strength of receiver's knowledge stock to enable knowledge transfer. There are other recognized limitations of this study. As the skills assessment method was evaluated in one case study only, issues of validity and reliability can be raised. Furthermore, this study investigates the knowledge stock of ICT staff only. More research should be conducted to assess broader skill set of employees and under different organisational settings. Nevertheless, we argue this research has presented a novel perspective of receiver's knowledge stock for effective knowledge transfer. This perspective can have significant implications to practice in knowledge management.

\section{References}

Alavi, M., and Leidner, D. E. 2001. "Knowledge Management and Knowledge Management Systems: Conceptual Foundations and Research Issues," MIS Quarterly (25:1), pp. 107-136.

Argote, L., and Ingram, P. 2000. "Knowledge Transfer: A Basis for Competitive Advantage in Firms," Organizational Behavior and Human Decision Processes (82:1), pp. 150-169.

Armstrong, C. E., and Shimizu, K. 2007. "A Review of Approaches to Empirical Research on the Resource-Based View of the Firm," J ournal of Management (33:6), pp. 959-986.

Barafort, B., Shrestha, A., Cortina, S., and Renault, A. 2018. "A Software Artefact to Support StandardBased Process Assessment: Evolution of the Tipa ${ }^{\circledR}$ Framework in a Design Science Research Project," Computer Standards \& Interfaces (60), pp. 37-47.

Barney, J. 1991. "Firm Resources and Sustained Competitive Advantage," J ournal of Management (17:1), pp. 99-120.

Barney, J., Wright, M., and Ketchen J r, D. J . 2001. "The Resource-Based View of the Firm: Ten Years after 1991," J ournal of Management (27:6), pp. 625-641.

Bartram, D. 2004. "Assessment in Organisations," Applied Psychology (53:2), pp. 237-259.

Chatzoglou, P., Chatzoudes, D., Sarigiannidis, L., and Theriou, G. 2018. "The Role of Firm-Specific Factors in the Strategy-Performance Relationship: Revisiting the Resource-Based View of the Firm and the Vrio Framework," Management Research Review (41:1), pp. 46-73.

Chiu, C.-M., Hsu, M.-H., and Wang, E. T. 2006. "Understanding Knowledge Sharing in Virtual Communities: An Integration of Social Capital and Social Cognitive Theories," Decision Support Systems (42:3), pp. 1872-1888.

Cockburn, I. M., Henderson, R. M., and Stern, S. 2000. "Untangling the Origins of Competitive Advantage," Strategic Management J ournal (21:10-11), pp. 1123-1145.

Cohen, W. M., and Levinthal, D. A. 2000. Absorptive Capacity: A New Perspective on Learning and Innovation. Cornell University: Elsevier.

Colbert, A., Yee, N., and George, G. 2016. "The Digital Workforce and the Workplace of the Future." Academy of Management Briarcliff Manor, NY.

Cummings, J. L., and Teng, B.-S. 2003. "Transferring R\&D Knowledge: The Key Factors Affecting Knowledge Transfer Success," J ournal of Engineering and Technology Management (20:1-2), pp. 39-68.

Dayasindhu, N. 2002. "Embeddedness, Knowledge Transfer, Industry Clusters and Global Competitiveness: A Case Study of the Indian Software Industry," Technovation (22:9), pp. 551560.

Dhanaraj, C., Lyles, M. A., Steensma, H. K., and Tihanyi, L. 2004. "Managing Tacit and Explicit Knowledge Transfer in Ijvs: The Role of Relational Embeddedness and the Impact on Performance," J ournal of International Business Studies (35:5), pp. 428-442.

Doz, Y. L., Santos, J ., and Williamson, P. J . 2001. From Global to Metanational: How Companies Win in the Knowledge Economy. Boston, USA: Harvard Business Press.

Edvinsson, L., and Malone, M. S. 1997. Intellectual Capital: Realizing Your Company's True Value by Finding Its Hidden Brainpower. Harper Business: New York.

Eisenhardt, K. M., and Martin, J. A. 2000. "Dynamic Capabilities: What Are They?," Strategic Management Journal (21:10-11), pp. 1105-1121.

Empson, L. 2001. "Fear of Exploitation and Fear of Contamination: Impediments to Knowledge Transfer in Mergers between Professional Service Firms," (54:7).

Frank, A. G., and Ribeiro, J . L. D. 2014. "An Integrative Model for Knowledge Transfer between New Product Development Project Teams," Knowledge Management Research \& Practice (12:2), pp. 215-225. 
Frank, A. G., Ribeiro, J . L. D., and Echeveste, M. E. 2015. "Factors Influencing Knowledge Transfer between Npd Teams: A Taxonomic Analysis Based on a Sociotechnical Approach," R\&D Management (45:1), pp. 1-22.

Fullwood, R., Rowley, J., and Delbridge, R. 2013. "Knowledge Sharing Amongst Academics in Uk Universities," J ournal of Knowledge Management (17:1), pp. 123-136.

García-Morales, V. J., Lloréns-Montes, F. J., and Verdú-J over, A. J. 2008. "The Effects of Transformational Leadership on Organizational Performance through Knowledge and Innovation," British J ournal of Management (19:4), pp. 299-319.

Grant, R. M. 1996. "Toward a Knowledge-Based Theory of the Firm," Strategic Management J ournal (17:S2), pp. 109-122.

Gupta, A. K., and Govindarajan, V. 2000. "Knowledge Flows within Multinational Corporations," Strategic Management J ournal), pp. 473-496.

Harrison, J. S., Hitt, M. A., Hoskisson, R. E., and Ireland, R. D. 2001. "Resource Complementarity in Business Combinations: Extending the Logic to Organizational Alliances," Journal of Management (27:6), pp. 679-690.

Héliot, Y., and Riley, M. 2010. "A Study of Indicators of Willingness in the Knowledge Transfer Process," J ournal of Management \& Organization (16:3), pp. 399-410.

Hevner, A. R. 2007. "A Three Cycle View of Design Science Research," Scandinavian journal of information systems (19:2), p. 4.

Huber, G. P. 1991. "Organizational Learning: The Contributing Processes and the Literatures," Organization Science (2:1), pp. 88-115.

Huckaby, J., and Christensen, H. I. 2012. "A Taxonomic Framework for Task Modeling and Knowledge Transfer in Manufacturing Robotics," 26th AAAI Conference on Artificial Intelligence, Georgia Institute of Technology: USA, pp. 759-770.

Inkpen, A. C., and Pien, W. 2006. "An Examination of Collaboration and Knowledge Transfer: ChinaSingapore Suzhou Industrial Park," J ournal of Management Studies (43:4), pp. 779-811.

Judge, T. A. 1994. "Person- Organization Fit and the Theory of Work Adjustment: Implications for Satisfaction, Tenure, and Career Success," J ournal of Vocational Behavior (44:1), pp. 32-54.

Kristof, A. L. 1996. "Person-Organization Fit: An Integrative Review of Its Conceptualizations, Measurement, and Implications," Personnel psychology (49:1), pp. 1-49.

Kyriakopoulos, K., and De Ruyter, K. 2004. "Knowledge Stocks and Information Flows in New Product Development," J ournal of Management Studies (41:8), pp. 1469-1498.

Lai, J., Lui, S. S., and Tsang, E. W. 2016. "Intrafirm Knowledge Transfer and Employee Innovative Behavior: The Role of Total and Balanced Knowledge Flows," J ournal of Product Innovation Management (33:1), pp. 90-103.

Lam, W. 2005. "Successful Knowledge Management Requires a Knowledge Culture: A Case Study," Knowledge Management Research \& Practice (3:4), pp. 206-217.

Lawler III, E. E. 1994. "From Job-Based to Competency-Based Organizations," Journal of Organizational Behavior (15:1), pp. 3-15.

Leonard-Barton, D. 1995. Wellsprings of Knowledge: Building and Sustaining the Sources of Innovation. Boston, MA: Harvard Business School Press.

Leonard, D., and Sensiper, S. 1998. "The Role of Tacit Knowledge in Group Innovation," California Management Review (40:3), pp. 112-132.

Lin, H.-F. 2007. "Knowledge Sharing and Firm Innovation Capability: An Empirical Study," International J ournal of Manpower (28:3/4), pp. 315-332.

Lopez-Saez, P., Emilio Navas-Lopez, J., Martín-de-Castro, G., and Cruz-Gonzalez, J. 2010. "External Knowledge Acquisition Processes in Knowledge-Intensive Clusters," J ournal of Knowledge Management (14:5), pp. 690-707.

Machlup, F. 1979. "Stocks and Flows of Knowledge," Kyklos (32:1-2), pp. 400-411.

Minbaeva, D. B., Pedersen, T., Björkman, I., and Fey, C. F. 2014. "A Retrospective On: Mnc Knowledge Transfer, Subsidiary Absorptive Capacity, and Hrm,"J ournal of International Business Studies (45:1), pp. 52-62.

Newk-Fon Hey Tow, W., Venable, J ., and Dell, P. 2012. "How Organisations Know What They Know: A Survey of Knowledge Identification Methods among Australian Organisations," Australasian Conference on Information Systems (23rd : 2012), Geelong, Victoria: ACIS, pp. 1-10.

Nickerson, J . A., and Zenger, T. R. 2004. "A Knowledge-Based Theory of the Firm-theProblem-Solving Perspective," Organization Science (15:6), pp. 617-632.

Nonaka, I. 1994. "A Dynamic Theory of Organizational Knowledge Creation," Organization Science (5:1), pp. 14-37. 
Pant, A., Shrestha, A., Kong, E., and Ally, M. 2018. "A Systematic Literature Mapping to Investigate the Role of It in Knowledge Stock and Transfer," Pacific Asia Conference on Information Systems (PACIS), Japan.

Patterson, T. L., Goldman, S., McKibbin, C. L., Hughs, T., and J este, D. V. 2001. "Uscd PerformanceBased Skills Assessment: Development of a New Measure of Everyday Functioning for Severely Mentally Ill Adults," Schizophrenia Bulletin (27:2), pp. 235-245.

Polanyi, M. 2009. The Tacit Dimension. Chicago: University of Chicago press.

Power, R., and Cormican, K. 2015. "Towards Effective Knowledge Transfer in High-Tech Project Environments: Preliminary Development of Key Determinants," Procedia Computer Science (64), pp. 17-23.

Prince, M., Burns, D., Lu, X., and Winsor, R. 2015. "Knowledge and Skills Transfer between Mba and Workplace," J ournal of Workplace Learning (27:3), pp. 207-225.

Rupietta, C., and Backes-Gellner, U. 2017. "Combining Knowledge Stock and Knowledge Flow to Generate Superior Incremental Innovation Performance-Evidence from Swiss Manufacturing," J ournal of Business Research (in press) ).

SFIA. 2018. "The Skills Framework for the Information Age - Sfia." Retrieved 1 February, 2018, from https:// www.sfia-online.org/ en/reference-guide

Shrestha, A., Kong, E., and Cater-Steel, A. 2018. "Managing Knowledge and Learning for Process Improvement: A Software-Mediated Process Assessment Approach for It Service Management," in The Palgrave Handbook of Knowledge Management. Cham: Palgrave Macmillan, pp. 621-641.

Shrestha, A., Kong, E., and Collins, P. 2017. "Facilitating Knowledge Transfer for Innovation: Towards a Decision Support System to Identify Knowledge Stock in the Ict Profession," Proceedings of the 28th Australasian Conference on Information Systems (ACIS 2017): Australian Association for Information Systems.

Siemsen, E., Balasubramanian, S., and Roth, A. V. 2007. "Incentives That Induce Task-Related Effort, Helping, and Knowledge Sharing in Workgroups," Management Science (53:10), pp. 15331550.

Spender, J. C. 1996. "Making Knowledge the Basis of a Dynamic Theory of the Firm," Strategic Management J ournal (17:S2), pp. 45-62.

Tripathi, K., and Agrawal, M. 2014. "Competency Based Management in Organizational," Global J ournal of Finance and Management (6:4), pp. 349-356.

Tzabbar, D., Aharonson, B. S., Amburgey, T. L., and Al-Laham, A. 2008. "When Is the Whole Bigger Than the Sum of Its Parts? Bundling Knowledge Stocks for Innovative Success," Strategic Organization (6:4), pp. 375-406.

von Konsky, B., Miller, C., andJ ones, A. 2016. "The Skills Framework for the Information Age: Engaging Stakeholders in Ict Curriculum Design," J ournal of Information Systems Education (27:1), pp. 37-50.

Wang, S., and Noe, R. A. 2010. "Knowledge Sharing: A Review and Directions for Future Research," Human Resource Management Review (20:2), pp. 115-131.

Wasko, M. M., and Faraj, S. 2005. "Why Should I Share? Examining Social Capital and Knowledge Contribution in Electronic Networks of Practice," MIS Quarterly), pp. 35-57.

Wernerfelt, B. 1984. "A Resource-Based View of the Firm," Strategic Management J ournal (5:2), pp. 171-180.

Wiewiora, A., Trigunarsyah, B., Murphy, G., and Coffey, V. 2013. "Organizational Culture and Willingness to Share Knowledge: A Competing Values Perspective in Australian Context," International J ournal of Project Management (31:8), pp. 1163-1174.

Wiklund, J., and Shepherd, D. 2003. "Knowledge-Based Resources, Entrepreneurial Orientation, and the Performance of Small and Medium-Sized Businesses," Strategic Management Journal (24:13), pp. 1307-1314.

\section{Acknowledgements}

We thank Mr. Paul Collins, CEO of SkillsTx for his input in providing the digital skills assessment platform for our artefact. 